\title{
High Voltage Hall Accelerator Propulsion System Development for NASA Science Missions
}

\author{
Hani Kamhawi \\ NASA Glenn Research \\ Center \\ 21000 Brookpark Road \\ Cleveland, OH 44135 \\ 216-977-7435 \\ hani.kamhawi-1@nasa.gov \\ Luis Pinero \\ NASA Glenn Research \\ Center \\ 21000 Brookpark Road \\ Cleveland, OH 44135 \\ 216-977-7428 \\ luis.r.pinero@nasa.gov
}

\author{
Thomas Haag \\ NASA Glenn Research \\ Center \\ 21000 Brookpark Road \\ Cleveland, OH 44135 \\ 216-977-7423 \\ thomas.w.haag@nasa.gov \\ Todd Peterson \\ NASA Glenn Research \\ Center \\ 21000 Brookpark Road \\ Cleveland, OH 44135 \\ 216-433-5350 \\ todd.t.peterson@nasa.gov
}

\author{
Wensheng Huang \\ NASA Glenn Research \\ Center \\ 21000 Brookpark Road \\ Cleveland, OH 44135 \\ 216-433-5557 \\ wensheng.huang@nasa.gov
}

\author{
John Dankanich \\ NASA Marshall Space \\ Flight Center \\ Huntsville, AL 35812 \\ 256-544-3441 \\ john.dankanich@nasa.gov
}

\author{
Rohit Shastry \\ NASA Glenn Research \\ Center \\ 21000 Brookpark Road \\ Cleveland, OH 44135 \\ 216-433-6673 \\ rohit.shastry@nasa.gov
}

\author{
Alex Mathers \\ Aerojet Corporation - \\ Redmond \\ 11411 139th Place N.E. \\ Redmond, WA 98052 \\ 425-936-6670 \\ alex.mathers@aerojet.com
}

Abstract-NASA Science Mission Directorate's In-Space Propulsion Technology Program is sponsoring the development of a $3.8 \mathrm{~kW}$-class engineering development unit Hall thruster for implementation in NASA science and exploration missions. NASA Glenn Research Center and Aerojet are developing a high fidelity high voltage Hall accelerator (HiVHAc) thruster that can achieve specific impulse magnitudes greater than 2,700 seconds and xenon throughput capability in excess of $\mathbf{3 0 0}$ kilograms. Performance, plume mappings, thermal characterization, and vibration tests of the HiVHAc engineering development unit thruster have been performed. In addition, the HiVHAc project is also pursuing the development of a power processing unit (PPU) and xenon feed system for integration with the HiVHAc engineering development unit thruster. Colorado Power Electronics and NASA Glenn Research Center have tested a brassboard PPU for more than 1,500 hours in a vacuum environment, and a new brassboard and engineering model PPU units are under development. VACCO Industries developed a xenon flow control module which has undergone qualification testing and will be integrated with the HiVHAc thruster extended duration tests. Finally, recent mission studies have shown that the HiVHAc propulsion system has sufficient performance for four Discovery- and two New Frontiers-class NASA design reference missions.

\section{TABLE OF CONTENTS}

1. INTRODUCTION.................................................................1

2. HIVHAC SYSTEM DESCRIPTION ...................................2

3. HIVHAC ENGINEERING DEVELOPMENT UNIT TEST

RESULTS ..........................................................................

4. HIVHAC POWER PROCESSING UNIT.............................6

5. HIVHAC XENON FEED SYSTEM ....................................7

6. HIVHAC ENGINEERING DEVELOPMENT UNIT 2 TEST

ROADMAP

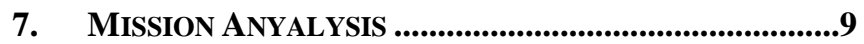

8. SUMMARY AND CONCLUSIONS...................................11

ACKNOWLEDGMENTS ..............................................................11

REFERENCES .............................................................................11

BIOGRAPHIES ............................................................................13

978-1-4673-1813-6/13/\$31.00 @2013 IEEE

\section{INTRODUCTION}

Electric propulsion (EP) systems can enable and enhance NASA's ability to perform scientific space exploration. [1] NASA Science Mission Directorate (SMD) planetary science missions to small bodies include fly-by, rendezvous, and smple return from a diverse set of targets. For example, NASA has successfully employed EP systems in the Deep Space 1 (DS1) and Dawn missions. [2, 3] To augment its capability to perform these and other solar system exploration missions, NASA continues to develop advanced EP technologies. [4] Recent small body mission studies indicate that the majority of these small body missions are enabled by the use of EP, and nearly all of the small body missions of interest are enhanced with EP. [5]

Electric propulsion systems performance can significantly reduce launch vehicle requirements, costs, and spacecraft mass because of its high specific impulse capability when compared to chemical propulsion. NASA SMD's In-Space Propulsion Technology (ISPT) Project funds new EP system development for future NASA science missions. [6] The two primary EP elements of this project are the development of NASA's Evolutionary Xenon Thruster (NEXT) ion thruster propulsion system [7] for NASA Flagship, New Frontiers and Discovery-class missions and the development of a long-life High Voltage Hall Accelerator (HiVHAc) [8] as a lower cost EP option for NASA Discovery-class science missions.

A recent study was performed to evaluate potential cost savings that can be realized by use of EP when compared to chemical propulsion for NASA Discovery-class missions. [9] A Hall thruster system can become cost competitive with alternative chemical propulsion systems if the Hall and chemical thrusters are held to the same fault tolerance. The Hall thruster system option will not only enable a wide range of Discovery-class missions, but will enable science 
return far greater than the chemical alternatives. Table 1 presents the cost savings that a Hall thruster propulsion system will provide over a gridded-ion propulsion system.

Table 1. Comparison of chemical and electric propulsion system (NEXT ion and Hall) delta costs for NASA Discovery class missions.

\begin{tabular}{|c|c|c|}
\hline Thruster & Config. & Cost $\Delta \$ \mathrm{M}$ \\
\hline $\begin{array}{c}\text { Chemical } \\
\text { Bipropellant }\end{array}$ & $1+0$ & Baseline \\
\hline NEXT $1^{\text {st }}$ User & $1+1$ & +26.5 \\
\hline NEXT ${ }^{\text {th }}$ User & $1+1$ & +7.0 \\
\hline Hall $1^{\text {st }}$ User & $1+1$ & +6.5 \\
\hline Hall $\mathrm{n}^{\text {th }}$ User & $1+1$ & +0.5 \\
\hline
\end{tabular}

This paper is organized as follows: Section 2 provides an overview of the projected HiVHAc system. Section 3 provides an overview of the HiVHAc engineering development unit thruster, designated EDU 2. Section 3 also presents a summary of EDU 2 thruster performance, thermal characterization, and random vibration test results. Section 4 provides an update on the HiVHAc power processing unit development options and details testing of a brassboard unit. Section 5 provides an update on the HiVHAc xenon feed system development. Section 6 discusses EDU 2 thruster and system test roadmap. Section 7 provides a summary of mission studies that compare HiVHAc thruster performance to a state-of-the-art (SOA) Hall propulsion system. Section 8 summarizes the content of this paper.

\section{HIVHAC SYSTEM DESCRIPTION}

The major elements of the high-specific impulse long-life Hall propulsion system that are being developed and matured include thruster, power processing unit (PPU), and xenon feed system (XFS) as is shown in Figure 1. The EDU 2 thruster development and testing are being performed by NASA Glenn and Aerojet. For the PPU development, the HiVHAc project has been leveraging and evaluating PPU developments that have been sponsored by industry and NASA's Small Business Innovative Research (SBIR) program but that can apply directly to a Hall propulsion system. The most mature PPU is a brassboard unit developed by Colorado Power Electronics (CPE). For XFS development, the HiVHAc project and Air Force Research Laboratory (AFRL) are furthering the development of an ISPT-funded advanced xenon flow control module (XFCM) by VACCO Industries. Status of the PPU and XFCM developments are detailed in later sections.

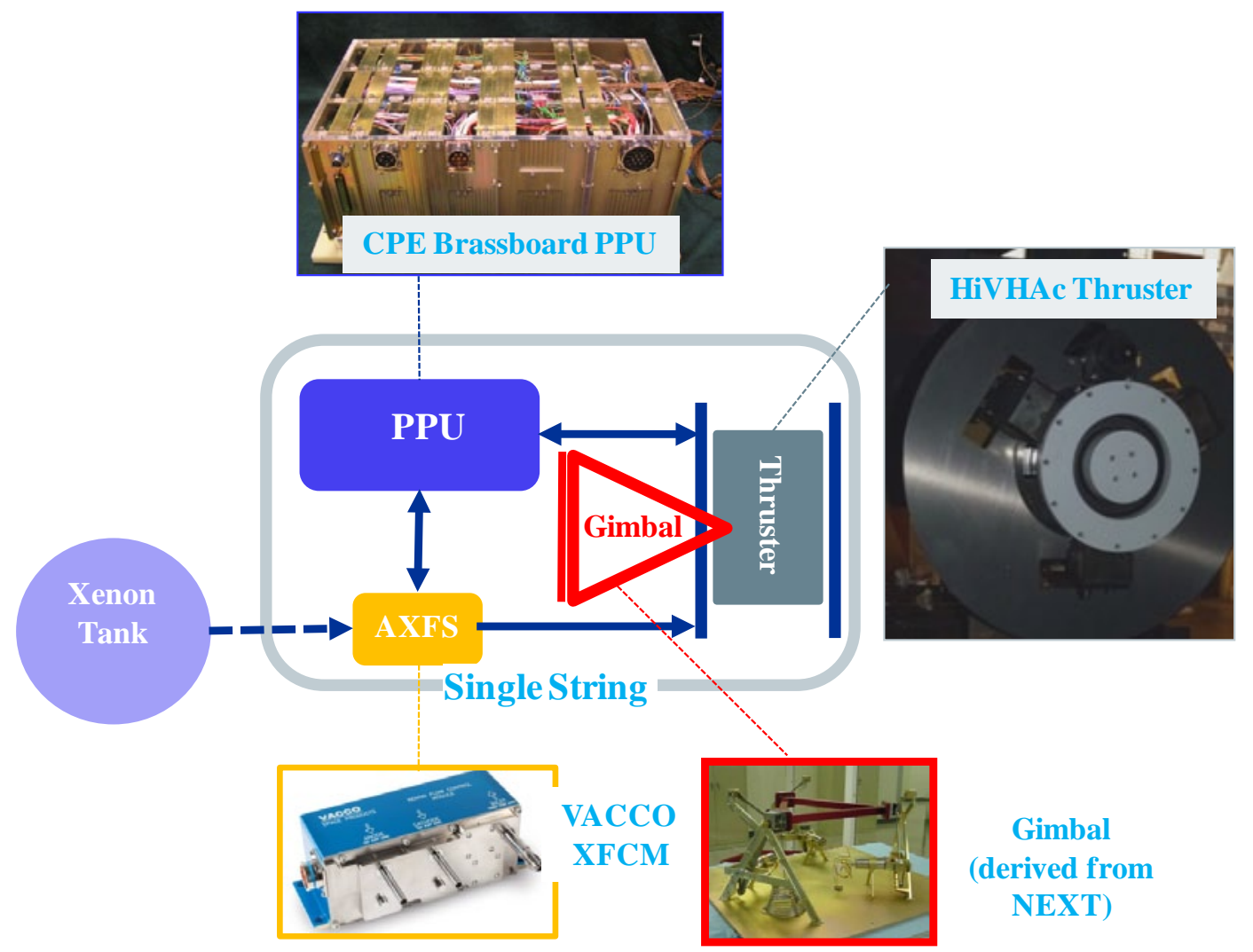

Figure 1 - Layout of the HiVHAc system showing its major sub-systems. 


\section{HiVHAC ENGINEERING DEVELOPMENT UNIT TEST RESULTS}

To demonstrate the HiVHAc project performance, throttleability, and lifetime goals, the NASA-77M and the NASA-103M.XL laboratory thrusters were built and tested. [10] The NASA-103M.XL (eXtended Life) incorporated an innovation that performs discharge channel replacement during thruster operation. [11, 12] Wear testing of the NASA-103M.XL thruster was performed to demonstrate the life-extending channel replacement innovation. The wear test demonstrated $>5,000$ hours of operation at a discharge voltage of $700 \mathrm{~V}$, which represents a xenon throughput of $>100 \mathrm{~kg}$. [11, 13] After the successful demonstration and validation of the life-extending channel replacement innovation with the NASA-103M.XL laboratory thruster, NASA Glenn teamed with Aerojet to design, manufacture, and test a high fidelity EDU thruster.

The goal of EDU 1 thruster design and manufacturing effort was to demonstrate a high fidelity HiVHAc thruster. [14] The EDU 1 thruster was designed to be throttleable with performance levels that meet or exceed levels achieved by the NASA-103M.XL laboratory thruster. The EDU 1 thruster design incorporated the life-extending channel replacement mechanism and was designed to survive anticipated environments.

Extensive functional and performance tests of EDU 1 thruster were performed. Although the thruster performance levels exceeded the design goals, [15] the tests revealed several areas that needed further refinement and design modifications and they are: the magnetic circuit, thermal management, discharge channel replacement mechanism, and high voltage insulator designs.

The magnetic circuit, thermal, and high voltage issues were addressed through redesign of certain thruster components. The magnetic circuit design changes resulted in a 10 percent higher peak radial magnetic field than initially measured but still lower than the design value. Significantly lower peak inner electromagnet operating temperatures were attained through redesign of the anode isolator and anode mount components. High voltage breakdowns were completely mitigated. Finally, several design modifications were implemented to the discharge channel replacement mechanism. These design modifications helped eliminate most of the causes for mechanism seizure. However, further testing of the thruster indicated that consistent and reliable mechanism operation would require additional redesign of several components of the discharge channel replacement mechanism. As such, NASA Glenn explored other mechanism options to perform the function of discharge channel replacement.
NASA Glenn proposed the implementation of a new mechanism to perform the discharge channel replacement function. There are several key features in the new mechanism.

- The new mechanism design is much simpler than the original mechanism design. The mass and number of components in the new mechanism is less than half that of the original mechanism.

- $\quad$ The new mechanism operation and actuation is less sensitive to the thruster internal thermal environment.

- $\quad$ The new mechanism occupies much less space than the original mechanism, which results in enhanced radiation losses and more efficient thermal management.

In addition, EDU 2 thruster incorporated new design features that include:

- A more efficient magnetic circuit that preserved EDU 1 thruster magnetic field topology while operating at lower electromagnet currents;

- An anode isolator and anode mount design that greatly enhanced heat conduction from the anode assembly;

- An electromagnet design that operates at lower temperatures; and

- A boron nitride discharge channel configuration that is structurally more robust than the original design.

\section{Performance Tests}

Performance Acceptance Testing (PAT) of EDU 2 thruster was performed in Vacuum Facility 12 (VF12) at NASA Glenn. Vacuum facility 12 is a 3-m diameter, 9-m long cylindrical cryopumped facility with a pumping speed of approximately 1,000,000 L/sec (air). Recent tests of VF12 indicate a base pressure of $8.9 \times 10^{-8}$ torr. A base pressure of approximately $1 \times 10^{-5}$ torr was attained at a xenon flow rate of $65 \mathrm{sccm}$. Vacuum facility 12 walls are lined with $1.3 \mathrm{~cm}$ thick graphite paneling to reduce the back-sputtered material flux to the thruster and test support hardware. An inverted pendulum thrust stand was used to measure thrust. [16] Performance acceptance testing of EDU 2 thruster was performed in December of 2011. The tested EDU 2 thruster did not include the discharge channel replacement mechanism because components were not yet available and the missing parts would not impact performance measurements. A thruster performance evaluation in April of 2012 was performed on an EDU 2 thruster configuration that included the discharge channel replacement mechanism and a flight cathode assembly; those performance results are reported in this paper. 
Figure 2 shows a photograph of the HiVHAc EDU 2 thruster while operating at $3.9 \mathrm{~kW}$ in VF12. During thruster operation the cathode was operated at a fixed flow rate of approximately $0.45 \mathrm{mg} / \mathrm{sec}$ and a 1 A keeper current was used during all test conditions reported hereafter. Figures 3 and 4 present the total efficiency and total specific impulse profiles for EDU 2 thruster, respectively. Representative error bars are included in Figures 3 and 4. The calculation of total efficiency and total specific impulse include cathode flow, cathode keeper power, and electromagnet power. Typical cathode and electromagnet power adds an additional 20 to $40 \mathrm{~W}$ to the thruster discharge power. Figure 3 indicates that peak total thruster efficiencies of 60 percent and 58 percent were achieved at $3.9 \mathrm{~kW}$ for discharge voltages of 600 and $650 \mathrm{~V}$, respectively. Figure 4, indicates that EDU 2 thruster demonstrated a peak total specific impulse of approximately 2,700 sec at $3.9 \mathrm{~kW}$ at a discharge voltage of $650 \mathrm{~V}$.

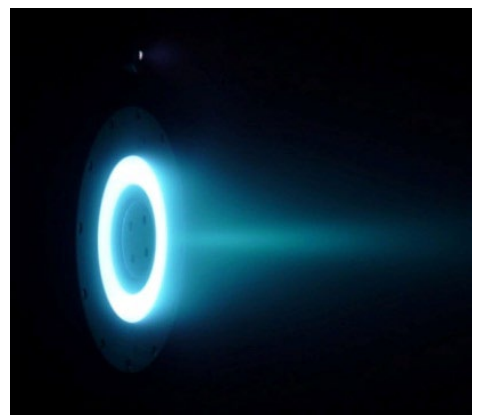

Figure 2 - Photograph of EDU 2 thruster while operating in VF12.

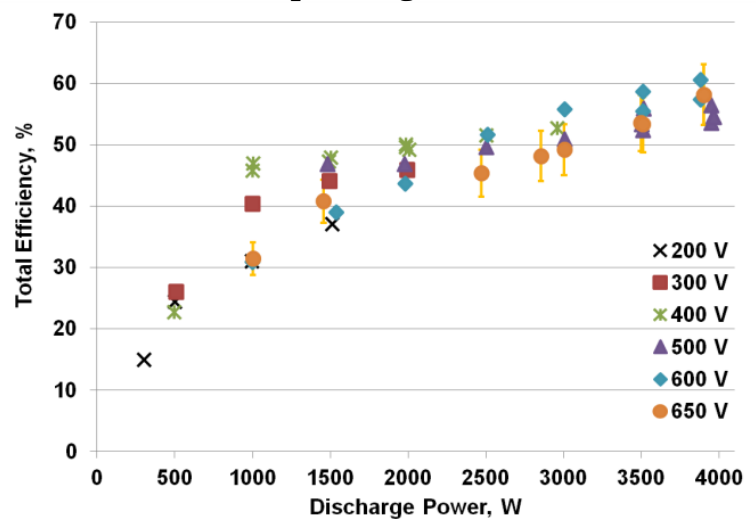

Figure 3 - Pre-vibration test EDU 2 thruster total efficiency vs. discharge power for discharge voltages between 200 and $650 \mathrm{~V}$.

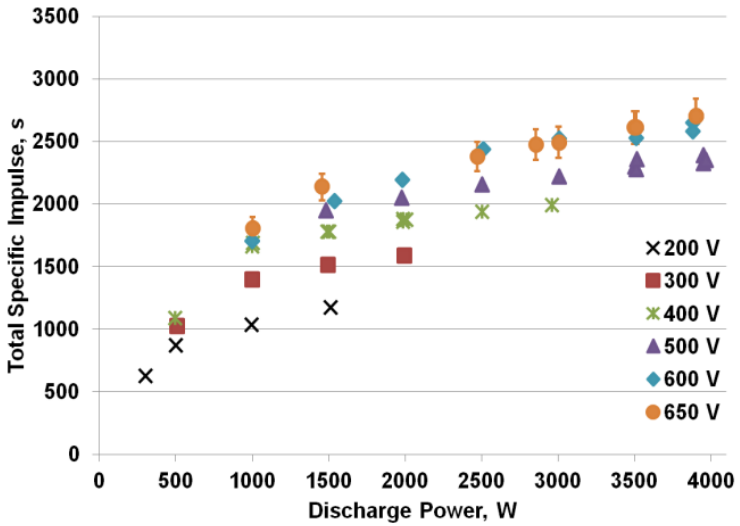

Figure 4 - Pre-vibration test EDU 2 thruster total specific impulse vs. discharge power for discharge voltages between 200 and $650 \mathrm{~V}$.

Vibration testing of EDU 2 thruster was performed at Aerojet during the week of May 7, 2012. After completion of the vibration test (test details are in the section labeled Vibration Tests), the thruster was shipped back to NASA Glenn and post-vibration inspections and performance evaluation were performed.

The post-test vibration inspection indicated that no obvious change to the thruster assembly occurred as a result of being subjected to a full qualification-level random vibration test. Post-vibration performance evaluation was again performed at power levels between 0.3 and $3.9 \mathrm{~kW}$. Figures 5 and 6 present a comparison between EDU 2 thruster pre- and postvibration test total thrust efficiency and specific impulse results at selected operating conditions. Results show that EDU 2 thruster performance pre- and post-vibration test is almost identical and is within the accuracy of the reported values.

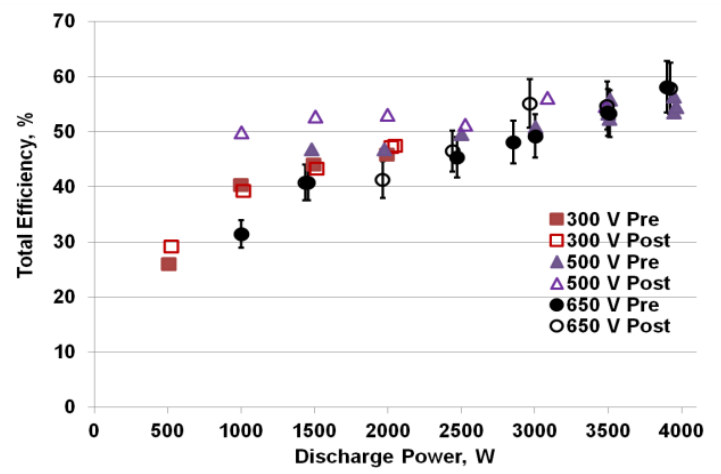

Figure 5 - EDU 2 thruster pre- and post-vibration test total efficiency vs. discharge power for selected discharge voltages. 


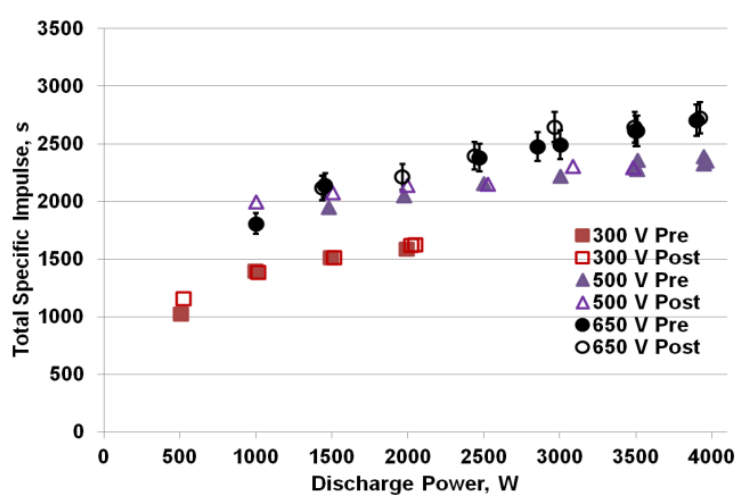

Figure 6 - EDU 2 thruster pre-and post-vibration test total specific impulse vs. discharge power for selected discharge voltages.

\section{Far-Field Ion Current Density Measurements}

Far-field current density measurements were performed in the EDU 2 thruster plume $450 \mathrm{~mm}$ from the discharge channel exit plane. Measurements were mainly made to assess the degree of plume divergence and to determine how plume divergence varies at various operating conditions. A second motivation for performing the measurements was to assess how the thruster plume profile varied due to subjecting EDU 2 thruster to a vibration test. Detailed farfield ion density measurements were presented by Huang et al. [17] Figure 7 presents a representative ion current density profile comparing the pre- and post-vibration test profiles for EDU 2 thruster operation at $2 \mathrm{~kW}$ and $650 \mathrm{~V}$. The study concluded that the plume divergence angle of the thruster was found to vary from $16^{\circ}$ to $28^{\circ}$ with higher discharge voltage conditions having lower ion beam divergence and that EDU 2 thruster plume underwent no meaningful change due to the thruster being subjected to vibration testing, which is consistent with post-test inspection and performance results.

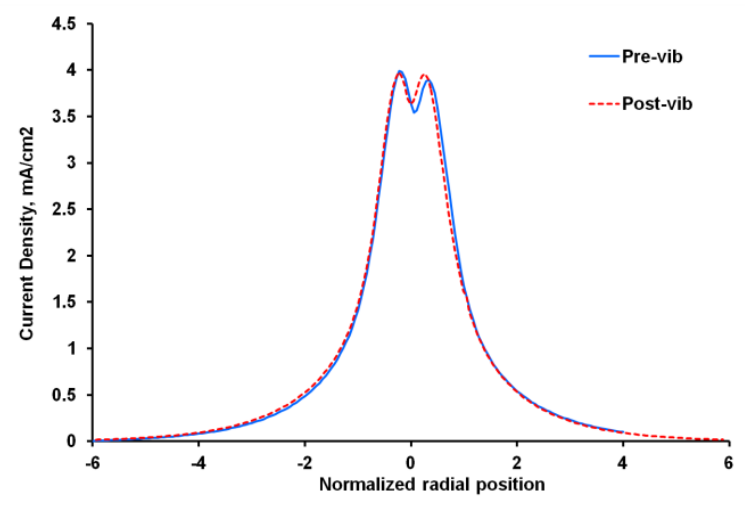

Figure 7 - Pre- and post- random vibration test ion current density profiles at $2 \mathrm{~kW}$ and $650 \mathrm{~V}$.

\section{Thermal Characterization Tests}

The EDU 2 thruster was instrumented with 14 type-k thermocouples to measure critical component temperatures. Temperature of the inner electromagnet, anode mount, anode isolator, inner and outer boron nitride discharge channels, backpole, and radiator were monitored and recorded during the thermal characterization tests. Temperature measurements of the EDU 2 thruster were made to confirm that the design changes alleviated the elevated temperatures that were measured during EDU 1 thruster tests. Additionally, insights gained from the temperature measurements will result in a better understanding of the power deposition into the thruster's internal components at various power levels. [18, 19, 20]

Component temperature measurements were performed for steady state thruster operation. Steady state temperature measurements were obtained for thruster operating at 2.5 $\mathrm{kW}\left(\mathrm{V}_{\mathrm{d}}=500 \mathrm{~V}\right.$ and $\left.\mathrm{I}_{\mathrm{d}}=5 \mathrm{~A}\right), 3.1 \mathrm{~kW}\left(\mathrm{~V}_{\mathrm{d}}=600 \mathrm{~V}\right.$ and $\mathrm{I}_{\mathrm{d}}=5$ A), $4.2 \mathrm{~kW}\left(\mathrm{~V}_{\mathrm{d}}=500 \mathrm{~V}\right.$ and $\left.\mathrm{I}_{\mathrm{d}}=8.25 \mathrm{~A}\right)$, and $4.2 \mathrm{~kW}\left(\mathrm{~V}_{\mathrm{d}}=650\right.$ $\mathrm{V}$ and $\left.\mathrm{I}_{\mathrm{d}}=6.52 \mathrm{~A}\right)$.

In general, the thermal characterization results confirmed that the design changes incorporated in the EDU 2 thruster alleviated the elevated inner electromagnet temperatures that were encountered during EDU 1 thruster tests. Peak inner electromagnet temperatures of approximately $480{ }^{\circ} \mathrm{C}$ were measured at $4.2 \mathrm{~kW}$. In addition, measurements of the discharge channel wall temperatures indicate that peak boron nitride discharge channel temperatures of $\sim 600{ }^{\circ} \mathrm{C}$ were recorded at $4.2 \mathrm{~kW}$. Detailed tabulation of the thermal characterization results is beyond the scope of this paper, but details of the results as well as detailed thermal modeling and analysis of the results will be performed and presented in an upcoming paper.

\section{Vibration Tests}

Vibration tests of the EDU 2 thruster were performed to verify that the thruster design, which includes a discharge channel replacement mechanism, is able to withstand and survive the random vibration test loads that are consistent with Delta-class launch vehicles and typical placement of electric propulsion thruster on spacecraft. [21] Vibration testing of the EDU 2 thruster was performed at Aerojet's vibration test laboratory in Redmond, Washington during the week of May 7, 2012. The EDU 2 thruster that was subjected to the vibration test is the same hardware that underwent hot-fire testing in April, 2012. No alterations or modifications were performed on the thruster configuration after the performance test and prior to the vibration test. Three A-frame arms and associated brackets were attached to the EDU 2 thruster prior to the vibration test. The Aframe arms were installed to simulate the presence of a thrust vector gimbal, providing vibration transfer characteristics and applied loads more representative of a 
likely flight configuration. No functional gimbal was used in this testing because gimbal designs tend to be spacecraft specific and the HiVHAc thruster has not yet been selected for a mission.

The qualification level test specifications are presented in Table 2 and are identical to levels used in qualification testing of the NEXT thruster. [22] The power spectral density listed in Table 2 results in an overall vibration level of $11.4 \mathrm{G} \mathrm{rms}$, and is performed in each of three orthogonal axes for 3 minute duration per axis.

Table 2. Assembly Qualification Random Vibration Test Acceleration Inputs.

\begin{tabular}{|c|c|c|}
\hline Assembly & Frequency, Hz & Qual., PF Level \\
\hline & $20 \mathrm{~Hz}$ & $0.04 \mathrm{G}^{2} / \mathrm{Hz}$ \\
& $20-50 \mathrm{~Hz}$ & $+3 \mathrm{~dB} /$ Octave \\
Thruster and & $50-600 \mathrm{~Hz}$ & $0.1 \mathrm{G}^{2} / \mathrm{Hz}$ \\
Gimbal & $600-2000 \mathrm{~Hz}$ & $-6 \mathrm{~dB} /$ octave \\
& $2000 \mathrm{~Hz}$ & $0.03 \mathrm{G}^{2} / \mathrm{Hz}$ \\
& Overall & $11.4 \mathrm{Grms}$ \\
\hline
\end{tabular}

Vibration tests in the two radial directions ( $\mathrm{X}$ and $\mathrm{Z}$ axes) were performed first, and then testing was performed along the thrust axis ( $\mathrm{Y}$ axis). The first axis tested was the $\mathrm{X}$-axis. For each axis, the first test performed was a low level sine sweep over the frequency range of 5 to 2,000 Hz. A uniform vibration level of $0.5 \mathrm{~g}$ was maintained, with a frequency sweep rate of two octaves per minute. This was followed by random vibration at reduced level for about one minute, and then full-level testing for 180 sec. Upon completion of the 3 minute random vibration test the low level sine sweep was repeated. An identical sequence was carried out for the $\mathrm{Z}$ axis. Upon completion of the radial axes testing ( $\mathrm{X}$ and $\mathrm{Z}$ ), the shaker table was re-configured for longitudinal (thrust axis-Y) testing. For all three axes tested, the thruster hardware and fixture plate were instrumented with fifteen accelerometers. The accelerometers were placed on the fixture plate, the A-frame bracket, the cathode keeper plate, the cathode bracket, the inner and outer boron nitride discharge channels, and the radiator.

Vibration test results and thruster inspection after test completion indicated that the thruster withstood and survived qualification level loads specified in Table 2. Inspection of thruster hardware after each axis sweep confirmed that all visible thruster components were still in their original assembled configuration.

\section{HiVhAc Power Processing Unit}

The HiVHAc PPU functional requirements are that it can operate over a 0.3 to $3.8 \mathrm{~kW}$ output power throttling range, and can supply output voltages between 200 and $700 \mathrm{~V}$ for input voltages between 80 and $160 \mathrm{~V}$. Environmental PPU requirements were derived from the NEXT thruster requirements documents. [22]

NASA is looking at various options to perform some critical design and testing of PPU converter topologies dependent on funding availability. The near term plan is to leverage converter/PPU development by other projects. One option is to implement new discharge modules that are being developed by Aerojet. [23] Another option is to leverage Hall thruster PPU developments within NASA's SBIR program. Three SBIR projects are developing wide range discharge modules for integration with Hall thrusters. The SBIR projects are the Busek Company Inc. "High Efficiency Hall Thruster Power Converter”, Colorado Power Electronics (CPE) Inc. "Low Cost High Performance Hall Thruster Support System”, and Arkansas Power Electronics International Inc. "Silicon Carbide PPU For Hall Effect Thrusters”.

The highest maturity SBIR program produced PPU is a CPE-designed and built PPU shown in Figures 8 and 9. The PPU contains two high voltage discharge modules, cathode heater and keeper power modules, and two electromagnet power modules. The $3.8 \mathrm{~kW}$ output power PPU can operate at input voltages between 80 and $160 \mathrm{~V}$ and is capable of output voltages between 200 and 725 V. [24] The unit's modules use an innovative three-phase resonant topology capable of efficiently delivering full power over the wide input and output voltage ranges. Extensive atmospheric and vacuum testing of the CPE discharge modules was performed at NASA Glenn and was reported in Reference [25].

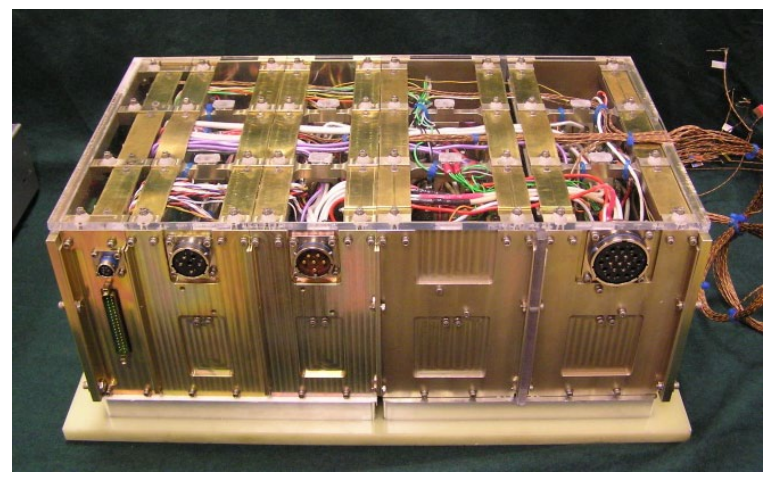

Figure 8 - Photograph of the Colorado Power Electronics brassboard PPU. 


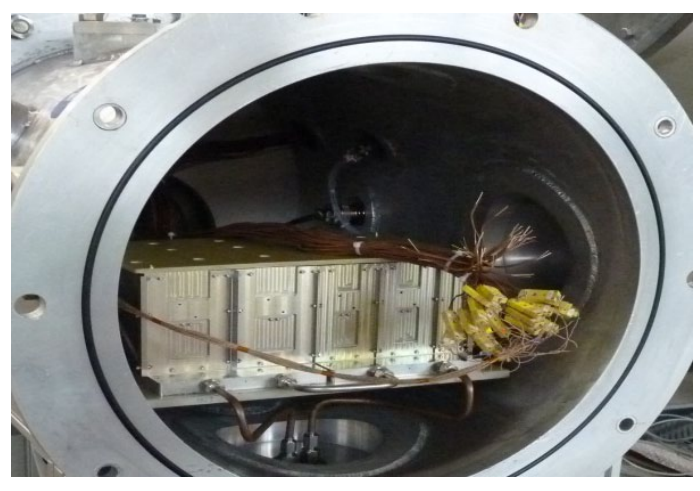

Figure 9 - Photograph of the Colorado Power Electronics brassboard PPU inside VF-70.

Extensive testing of CPE PPU has been performed over the past year. The CPE PPU was used to power EDU 2 thruster during the various performance tests that were reported in this paper. In addition, CPE's PPU has undergone a 1,500hour vacuum burn-in test at $3.5 \mathrm{~kW}$ output power into a resistive load. During the 1,500 hour test, temperature readings of twenty critical PPU components were monitored and recorded at various operating discharge current and voltage settings and at different base plate operating temperatures. Under a Phase II SBIR project, CPE is developing another brassboard unit and an engineering development unit. The enhanced brassboard PPU is scheduled to be delivered to NASA Glenn in March of 2013. Upon receipt of the enhanced brassboard PPU it will undergo extensive benchtop testing and will undergo a 500hour burn-in vacuum test. The unit will also be subjected to thermal vacuum tests followed by random vibration testing at NASA Glenn's Structural Dynamic Laboratory (SDL). The planned burn-in and environmental tests will identify any design refinements that have to be incorporated in the EDU PPU that is planned to be delivered to NASA Glenn in February of 2014.

\section{HiVHAC XENON FEED SySTEM}

In 2008, the HiVHAc thruster was hot-fire tested with VACCO's first generation xenon feed system. [26] As a result of the successful testing of the HiVHAc thruster with the VACCO xenon feed system, NASA GRC and AFRL acquired a flight-like VACCO advanced xenon feed system for integration with the HiVHAc propulsion system and other EP devices of interest to the Air Force. The VACCO xenon flow control module (XFCM) is a low-cost, lightweight, low-power consumption xenon feed system, which represents a dramatic improvement over the NSTAR flight feed system and also an additional 70 percent reduction in mass, 50 percent reduction in footprint, and 50 percent reduction in cost over the baseline NEXT xenon feed system. The XFCM is designed as a two channel electronic flow controller with a series redundancy to protect against leakage. It includes integral pressure and temperature sensors. The unit is designed to withstand and comply with the vibration, thermal, and shock loads environments for NASA missions.

The XFCM unit was delivered to NASA GRC in June of 2012. Compliance with the flow accuracy, power consumption, vibration environment, shock environment, thermal environment, and minimum and maximum inlet pressure operation was demonstrated by test. Figure 10 presents a layout and picture photograph of the XFCM. Table 3 lists some of the XFCM specifications. Testing of the XFCM unit with the HiVHAc EDU 2 thruster and CPE brassboard PPU are planned for the Spring of 2013.

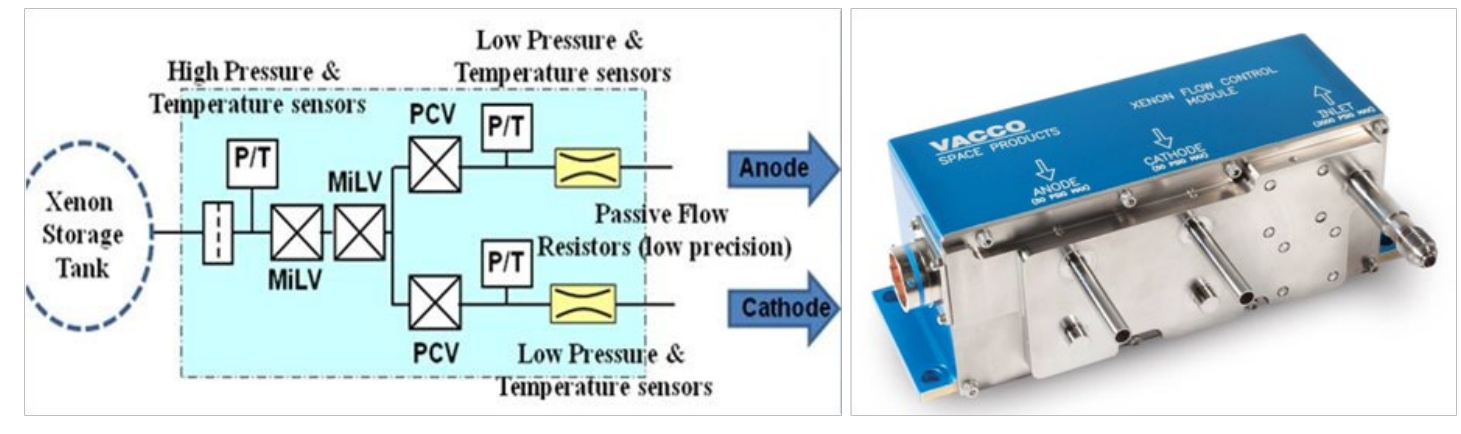

Figure 10 - VACCO XFCM layout and photograph.

Table 3. VACCO XFCM Specifications

\begin{tabular}{|l|l|}
\hline Inlet Pressure Range & 10 to 3000 psia \\
\hline Anode Flow Range & 0 to 80 sccm Xenon \\
\hline Cathode Flow Range & 0 to 80 sccm Xenon \\
\hline Flow Accuracy & $\begin{array}{l} \pm 3 \% \text { of Set Value } \\
\text { (closed loop) }\end{array}$ \\
\hline
\end{tabular}

\begin{tabular}{|l|l|}
\hline Internal Leakage & $10 \times 10^{-3}$ scch GHe \\
\hline External Leakage & $1.0 \times 10^{-6} \mathrm{sccs}$ \\
\hline Lifetime & $\begin{array}{l}10 \text { years, 7,300 cycles, } \\
100 \% \text { margin }\end{array}$ \\
\hline Mass & $<1.25 \mathrm{~kg}$ \\
\hline Power Consumption & $<1 \mathrm{~W}$ steady state \\
\hline Size $(\mathrm{W} \times \mathrm{H} \times \mathrm{D})$ & $19.5 \mathrm{~cm} \times 7 \mathrm{~cm} \times 7.5 \mathrm{~cm}$ \\
\hline
\end{tabular}




\section{HIVHAC ENGINEERING DEVELOPMENT UNIT 2 THRUSER TEST ROADMAP}

The EDU 2 thruster test roadmap is shown in Figure 11. The roadmap signifies the path the EDU 2 thruster will pursue to demonstrate its flight worthiness and its service life capability. The test readiness boxes shown in Figure 11 with a green fill/background indicate completed tasks and tests. The next steps in the EDU 2 thruster test plan include performing an abbreviated performance map of the thruster followed by a short duration test to verify the discharge channel replacement mechanism operation; the test duration is expected to be between 1,000 to 2,000 hours. Upon completion of the aforementioned test, the eroded boron nitride channels will be replaced with new channels and a reference performance map of the thruster will be conducted. Then the thruster will be shipped to the Jet Propulsion Laboratory (JPL) for a thermal vacuum test, after which it will be returned to NASA Glenn to undergo another abbreviated performance map to confirm that thruster operation and performance were not altered due to being subjected to a thermal vacuum environment. Then performance and plume tests will be completed in Vacuum Facility 5 (VF5) at NASA Glenn to baseline thruster performance under lower background pressure conditions. Finally, the thruster will be installed in VF12 for baseline testing and plasma diagnostics checkouts, and then a wear test will be initiated.

The plume diagnostics that will be implemented during the wear testing of EDU 2 thruster are needed to collect a large amount of information about the operating characteristics of the thruster. By studying the thruster plume, it is possible to quantify a number of physical phenomena that drive the thrust production process. The associated data can be used to assess the health of the thruster and diagnose any issues that may arise. Additionally, the plume contains energetic particles that can potentially influence the operation of other components on a spacecraft. The plume characterization tests will also provide a set of baseline values for reference for subsequent wear tests.

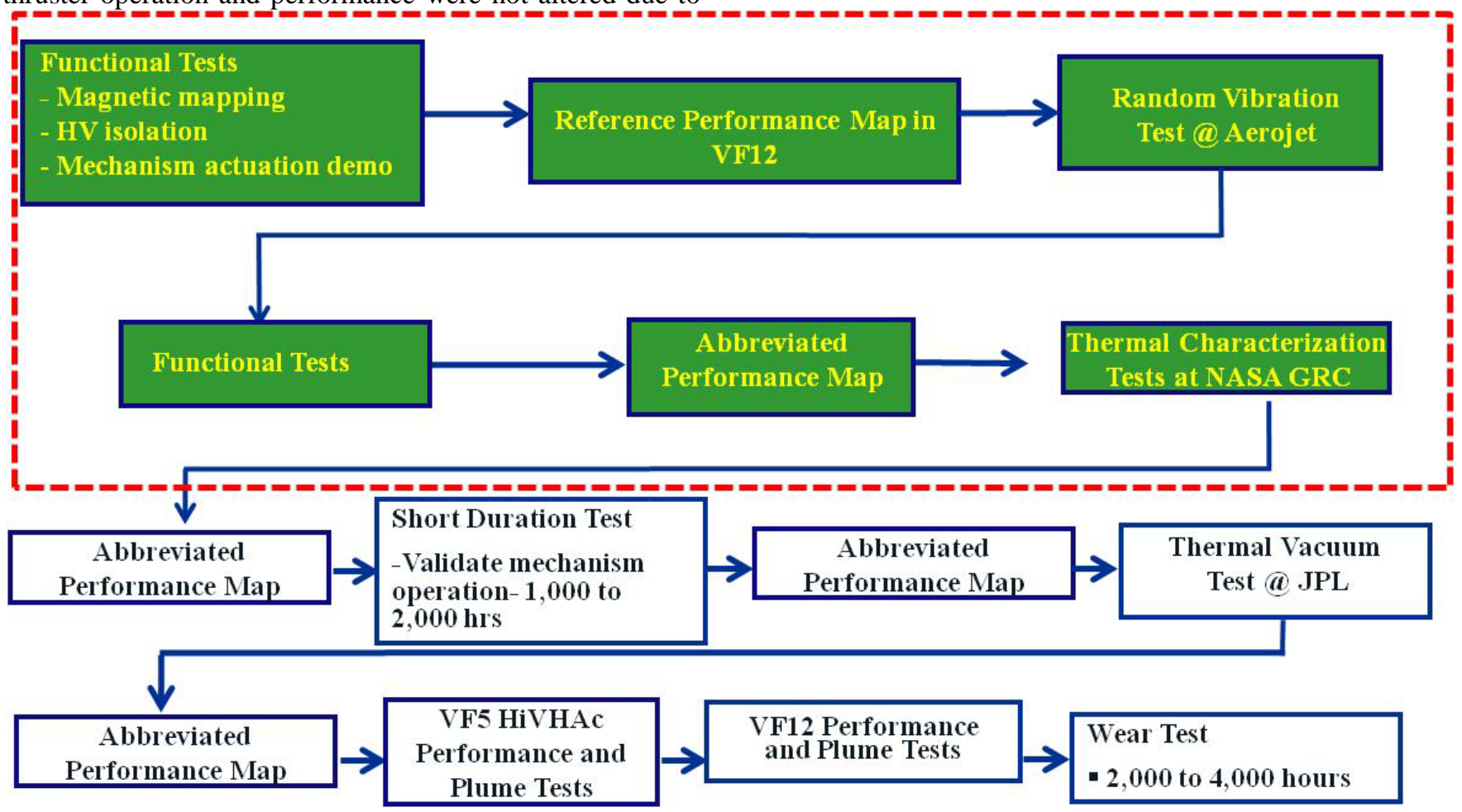

Figure 11 - EDU 2 thruster test roadmap, green boxes indicate completed tests.

A "phenomenological efficiency model" is typically used to assess Hall thruster efficiency. A typical phenomenological efficiency model is composed of five factors. They are mass utilization efficiency, charge utilization efficiency, current utilization efficiency, voltage utilization efficiency, and plume divergence efficiency. [27, 28, 29]

To properly monitor the health of the HiVHAc thruster, the above five factors will be tracked as a function of time. This will be accomplished by placing a Faraday probe, a ExB probe, and a retarding potential analyzer on motorized stages in the far-field of the thruster. Additionally, a Langmuir probe will also be used to measure plasma temperature and plasma potential in the plume of the thruster. The data obtained from these four probes are also the same data needed to perform spacecraft interaction studies. Thus, two goals can be accomplished with the same diagnostics set. 
In additional to the above-mentioned plasma diagnostics, several erosion and back-sputter diagnostics will be deployed for the wear test. For the wear test, additional data will be collected regarding the state of erosion in the thruster discharge channel walls. Data are needed to confirm the channel replacement mechanism is functioning correctly. The diagnostics that will be added include a vacuum laser profilometer, a set of quartz crystal microbalances (QCMs), and pinhole cameras. The purpose of the laser profilometer is to scan the channel walls of the thruster for shape changes that will indicate operation of the channel replacement mechanism. Those scans will also be used to calculate the erosion rate of the discharge channel walls. The QCMs will be used to measure back-sputter rate of background material onto the thruster. This information is useful for determining the fidelity of the test environment and what correction, if any, is needed on the erosion rate measurement. The pinhole camera will be analyzed post-test for the chemical composition of the back-sputtered deposit.

\section{Mission Analysis}

In 2004, mission studies found that for certain NASA Discovery-class science missions, a Hall thruster system with performance characteristics similar to the HiVHAc thruster resulted in substantial cost and performance benefits when compared to the NASA Solar Electric Propulsion Technology Application Readiness (NSTAR) and NEXT ion engine. [10, 30, 31 32]

Additional mission studies were performed to evaluate the performance of the HiVHAc $3.8 \mathrm{~kW}$ thruster and a SOA 4.5 kW Aerojet flight Hall thruster designated BPT-4000. [33] The mission studies results were updated with recent HiVHAc and BPT-4000 throttle tables that reflect improved and extended thruster operating performance results. The recent mission studies utilized the HiVHAc performance results reported in this paper which included thruster operation in two modes: a high-specific impulse and a high thrust-to-power mode. Additionally, the BPT-4000 throttle table used in these mission studies incorporated results from recent $\mathrm{BPT}-4000$ tests at high discharge voltage that demonstrated BPT-4000 thruster operation at high specific impulse. [34] The recent mission studies included evaluation of the HiVHAc and BPT-4000 thruster operation for four NASA Discovery-class design reference missions (DRMs), two New Frontiers-class DRMs, and one Flagshipclass DRM. [35] The evaluated missions included:
- Discovery-class Vesta-Ceres rendezvous mission (i.e., Dawn Mission), which has both time constraints and a very high post launch $\Delta \mathrm{V}$, requiring both moderate thrust-to-power and a higher specific impulse than a conventional Hall thruster;

- Discovery-class Koppf comet rendezvous (CR) mission, which has few constraints and does not thrust in gravity wells (this favors a high specific impulse throttle table);

- Discovery-class Near-Earth Asteroid Return Earth Return (NEARER) mission;

- Discovery-class Nereus sample return (NSR) mission which is a relatively low $-\Delta \mathrm{V}$ mission with time constraints, favorable for a higher thrust-topower thruster;

- New Frontiers-class Wirtanen comet surface sample return (CSSR), a 2004 New Frontiers Design Reference Mission target with a $12 \mathrm{~km} / \mathrm{s}$ post launch $\Delta \mathrm{V}$ for a 7 year sample return;

- New Frontiers-class Churyumov-Gerasimenko (CG) CSSR, a 2012 Decadal Survey design reference mission target with a $7-10 \mathrm{~km} / \mathrm{s}$ post launch $\Delta \mathrm{V}$ for a 12 year sample return, depended on the thruster;

- Flagship-class Uranus Orbiter with probe mission from the 2012 Planetary Science Decadal Survey design reference mission. The electric propulsion is used to augment the mass to Uranus to allow for a chemical orbit insertion and satellite tour.

Results from the mission studies indicated that the HiVHAc thruster was able to exceed the needs of all the evaluated missions except for the Uranus Orbiter Flagship-class mission. For the various Discovery- and New Frontiersclass missions that were evaluated, the HiVHAc thruster performance was sufficient; moreover, the high thrust-topower throttle table operation typically provided higher performance than the high specific impulse thruster operation. The BPT-4000 SOA thruster with its extended power and discharge voltage throttle table had sufficient performance for the Koppf CR, NEARER, and Nereus SR missions but had insufficient performance for the Dawn mission. In addition, the BPT-4000 thruster had insufficient performance for the two New Frontiers-class and one Flagship-class missions that were evaluated. Figures 12 and 13 show a comparison between the HiVHAc and BPT-4000 thrusters performance for the Dawn Discovery-class and CG CSSR New Frontiers-class missions, respectively. 


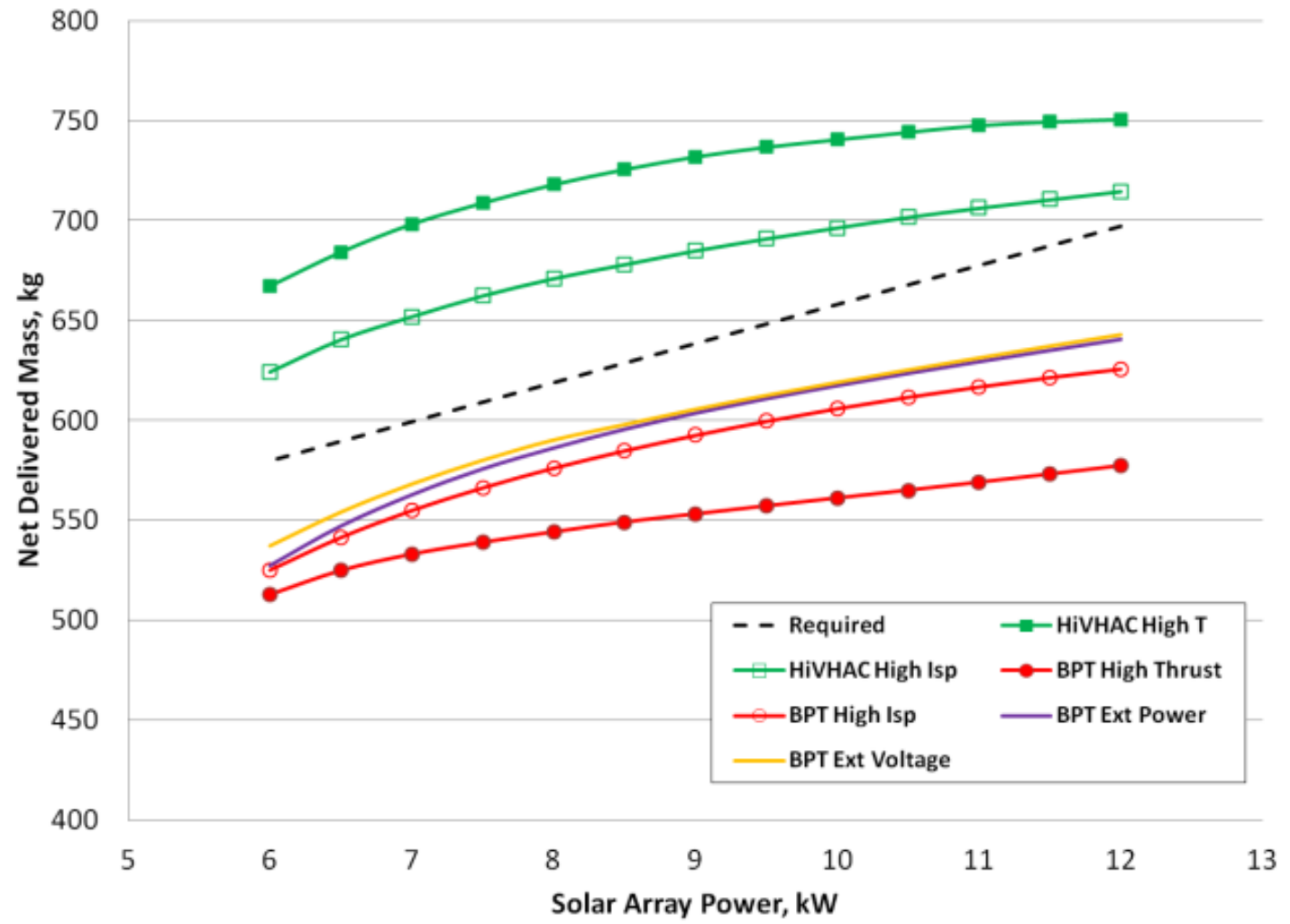

Figure 12 - HiVHAc and BPT-4000 performance for the Dawn Discovery-class mission.

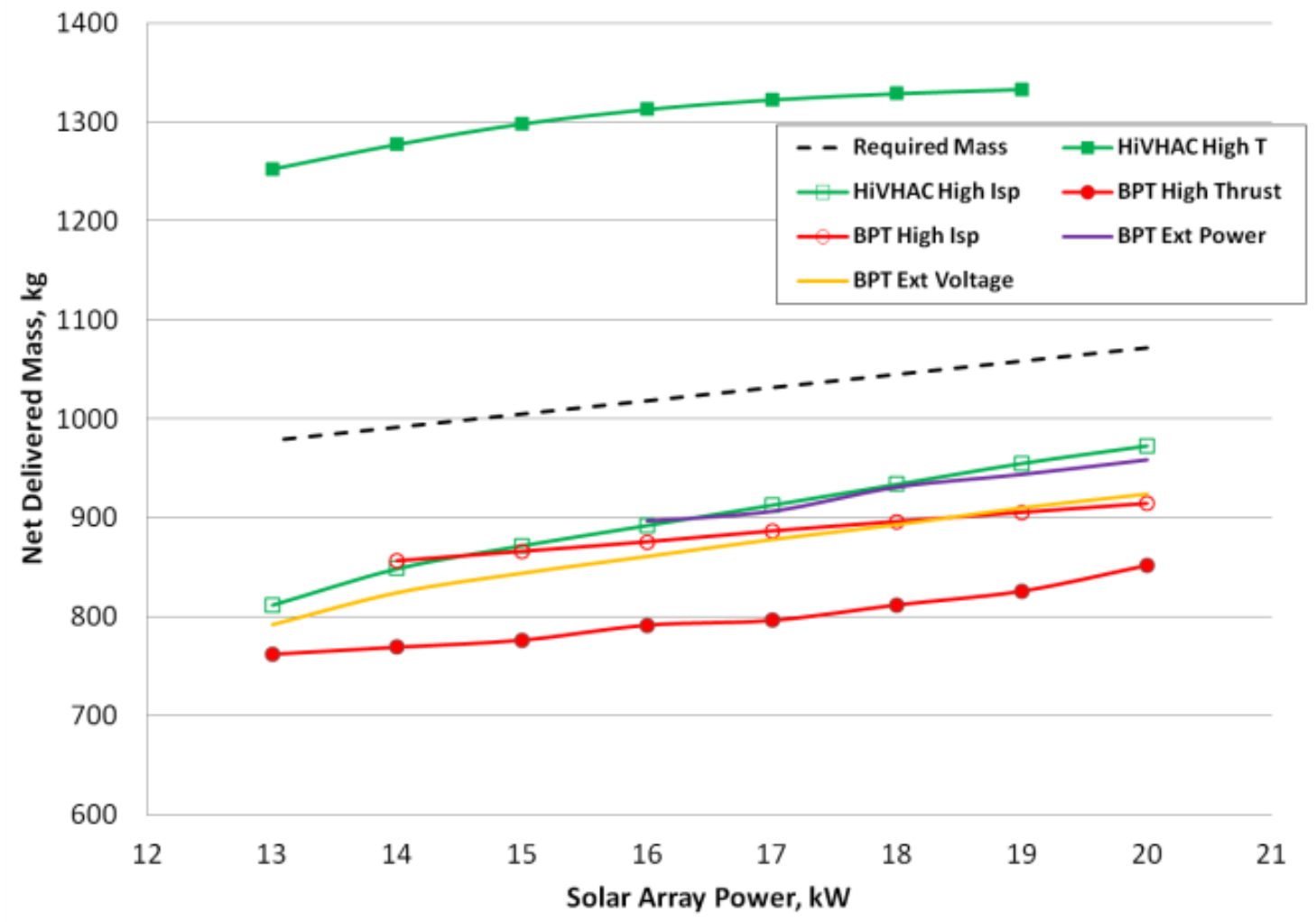

Figure 13 - HiVHAc and BPT-4000 performance for the C-G CSSR New Frontiers-class mission. 


\section{SUMMARY AND CONCLUSIONS}

Functional and performance testing of EDU 2 thruster was completed over power levels between 0.3 and $3.9 \mathrm{~kW}$. Testing of EDU 2 thruster indicated that the thruster operation was nominal across the entire operating power range. At $3.9 \mathrm{~kW}$ and a discharge voltage of $650 \mathrm{~V}$ the thruster achieved a total thrust efficiency of $58 \%$ and a total specific impulse of 2,700 sec. Thermal characterization test results indicated that peak measured component temperatures are below the prescribed thruster materials' maximum operating temperatures.

Full-level random vibration testing of the EDU 2 thruster was performed in three axes: $\mathrm{X}$ and $\mathrm{Z}$ axes (lateral) and the $\mathrm{Y}$ axis. Inspection of the thruster hardware after each test cycle confirmed that the thruster withstood and survived the full-level applied loads. No changes to the assembled thruster configuration were observed. Post-vibration test performance evaluation confirmed that the thruster performance was not altered due to being subject to a fulllevel three axes random vibration test.

Development of the HiVHAc power processing unit and xenon feed system is ongoing. A brassboard power processing unit developed by Colorado Power Electronics, Inc. has undergone extensive functional and operational testing with EDU 2 thruster and with a resistive load. A 1,500-hour, vacuum burn-in test was performed at $3.5 \mathrm{~kW}$ output power, the test included monitoring and recording of the temperature of twenty components. Development of a next generation brassboard PPU is being performed by CPE. A VACCO xenon flow control module unit that has undergone qualification testing was recently delivered to NASA Glenn, the unit will be incorporated in future EDU 2 thruster tests.

Finally, recent mission studies were performed for Discovery-, New Frontiers-, and Flagship-class missions using recent HiVHAc thruster and extended BPT-4000 performance results. The results indicate that the HiVHAC thruster provides maximum mission capture for Discoveryclass missions and also for both of the New Frontiers-class mission evaluated. The BPT-4000 thruster with extended capability does improve performance and mission capture, but does not match the HiVHAc thruster performance. Also, the HiVHAc system offers the highest mission capture while requiring the lowest spacecraft power; expecting to save significant total spacecraft cost and mass. The overall results highlight the potential for the HiVHAc Hall propulsion system to cost enable electric propulsion for NASA's Discovery-class missions.

\section{ACKNOWLEDGMENTS}

The work described in this paper is funded by NASA's Science Mission Directorate In-Space Propulsion
Technology office. The authors would also like to thank Kevin Blake, Mike Pastel, Richard Pollack, Kevin McCormick, George Readus, and George Jacynycz for their relentless support of the HiVHAc project.

\section{REFERENCES}

[1] Committee on the Planetary Science Decadal Survey Space Studies Board, "Vision and Voyages for Planetary Science in the Decade 2013-2022."

[2] Sovey, J. S., Rawlin, V. K., and Patterson, M. J., "Ion Propulsion Development Projects in U.S.: Space Electric Rocket Test to Deep Space 1,” Journal of Propulsion and Power, Vol. 17, No. 3, May-June 2001, pp. 517-526.

[3] Russel, C. T., et al., "Dawn: A Journey to the Beginning of the Solar System," DLR International Conference on Asteroids, Comets, and Meteors, July-August 2002.

[4] NASA's Science Mission Directorate Science Plan for 2007-2016.

[5] Dankanich, J. W., "Electric Propulsion for Small Body Missions”, AIAA Paper 2010-6614, August 2010.

[6] Pencil, E., et al., "Overview of NASA's Electric Propulsion Development Activities for Robotic Science Missions”, IEPC Paper 2011-161, September 2011.

[7] Benson, S., Patterson, M, and Snyder, S., "NEXT Ion Propulsion System Progress Towards Technology Readiness,” AIAA Paper 2008-5285, July 2008.

[8] Kamhawi, H., et al., "Overview of the Development of a Low Cost High Voltage Hall Accelerator Propulsion System for NASA Science Missions,” AIAA Paper 20115520, July, 2011.

[9] Dankanich, J.W., Drexler, J. A., and Oleson, S. R., "Electric Propulsion Mission Viability with the Discovery-Class Cost Cap,” AIAA Paper 2010-6776, August 2010.

[10] Manzella, D., Oh, D., and Aadland, R., "Hall Thruster Technology for NASA Science Missions," AIAA Paper 2005-3675, Tucson, Arizona, 2005.

[11] Peterson, P., Kamhawi, H., Manzella, D., and Jacobson, D., "Hall Thruster Technology for NASA Science Missions: HiVHAc Status Update,” AIAA Paper 20075236, July 2007.

[12] Kamhawi, H., "Various Hollow Cathode Configurations Testing for the High Voltage Hall Accelerator," AIAA Paper 2007-5172, July 2007. 
[13] Kamhawi, H., Manzella, D., and Peterson, P., "High Voltage Hall Accelerator Wear Test Update,” presented at JANNAF, Orlando, Florida, December 2008.

[14] Mankins, J., “Technology Readiness Levels,” http://www.hq.nasa.gov/office/codeq/trl/trl.pdf.

[15] Kamhawi, H., et al., "Overview of the Development of a Low Cost High Voltage Hall Accelerator Propulsion System for NASA Science Missions,” AIAA Paper 20115520, July 2011.

[16] Haag, T., Osborn, M., "RHETT/EPDM Performance Characterization”, NASA/TM 1998-20622.

[17] Huang, W., Kamhawi, H., and Shastry, R., "Far-field Ion Current Density Measurements before and after the NASA HiVHAc EDU2 Vibration Test," AIAA Paper 2012-4195, July 2012.

[18] Kamhawi, H., Manzella, D., Mathers, A., and Aadland, R., "In-Space Propulsion High Voltage Hall Accelerator Thruster Development Project Overview," SPS-III-10, presented at JANNAF, December 2008.

[19] Mathers, A., Aadland, R., Manzella, D., and Kamhawi, H., "Development Status of the HiVHAC Thruster," AIAA Paper 2008-4524, July 2008.

[20] De Grys, K., Rayburn, C., and Hass, J., "Study of Power Deposition in the BPT-4000 Hall Thruster," AIAA Paper 2003-5277, July 2003.

[21] Snyder, J. S., et al., "Environmental Testing of the NEXT PM1Thruster,” AIAA Paper 2007-5275, July, 2007.

[22] "NEXT Technical Requirements and Validation Document," Internal memorandum, GRC-NEXT-200, November 2007.

[23] Sultan, A., et al., "Development of a Modular Hall Thruster Power Converter,” AIAA Paper 2011-5997, July 2011.

[24] Hesterman, B., "Wide Range Multi-Phase Resonant Converters,” JANNAF-1435, May 2010.

[25] Pinero, L. R., Kamhawi, H., and Drummond, G., "Integration Testing of a Modular Discharge Supply for NASA's High Voltage Hall Accelerator Thruster,” IEPC Paper 2009-275, September 2009.

[26] Dankanich, J., et al., “Advanced Xenon Feed System Development and Hot Fire,” AIAA Paper 2009-4910, August 2009.
[27] Brown, D. L., "Investigation of Flow Discharge Voltage Hall Thruster Characteristics and Evaluation of Loss Mechanisms", Ph.D. Dissertation, Aerospace Engineering, University of Michigan, Ann Arbor, MI, 2009.

[28] Hofer, R. R., et al., "Efficacy of Electron Mobility Models in Hybrid-PIC Hall Thruster Simulations”, 44th AIAA/ASME/SAE/ASEE Joint Propulsion Conference \& Exhibit, AIAA-2008-4924, Hartford, CT, 21-23 Jul., 2008.

[29] Reid, B. M., "The Influence of Neutral Flow Rate in the Operation of Hall Thrusters”, Ph.D. Dissertation, Aerospace Engineering, University of Michigan, Ann Arbor, MI, 2008.

[30] Oh, D. "Evaluation of Solar Electric Propulsion Technologies for Discovery Class Missions,” AIAA Paper 2005-4270, July 2005.

[31] Witzberger, K. E., et al., "NASA’s 2004 In-Space Propulsion Re-focus Studies for New Frontiers Class Missions,” AIAA Paper 2005-4271, July 2005.

[32] Jacobson, D., et al. "NASA's 2004 Hall Thruster Program,” AIAA Paper 2004-3600, July 2004.

[33] Dankanich, J., Kamhawi, H., and Mathers, A., "HiVHAc Maximum Operating Power Range,” IEPC Paper 2009213, September 2009.

[34] Hofer, R. R., et al. "High-Specific Impulse Operation of the BPT-4000 Hall Thruster for NASA Science Missions," AIAA Paper 2010-6623, July 2010.

[35] National Research Council, "Vision and Voyages for Planetary Science in the Decade 2013-2022”. 


\section{BIOGRAPHIES}

Hani Kamhawi is a Senior Propulsion Research Engineer at the NASA Glenn Research Center Propulsion and Propellants Branch. He leads the technical development of Hall thrusters for NASA missions; he is the principal investigator of the High Voltage Hall Accelerator thruster development project, and is the technical lead of the Office of Chief Technologist In Space Propulsion project at NASA Glenn. Dr. Kamhawi is the recipient of the NASA Silver Snoopy Award. Hani has a B.S., M.S., and Ph.D. in Aerospace Engineering from the Ohio State University.

Thomas Haag is an Aerospace Engineer at the NASA Glenn Research Center, Space Propulsion Branch. He has over 25 years of experience in the design and testing of electric propulsion thrusters. Tom has a B.S. in Mechanical Engineering and a M.S. in Engineering Science from Clarkson University.

Wensheng Huang is a Propulsion Research Engineer at the NASA Glenn Research Center Propulsion and Propellants Branch. He is primarily involved in the technical development of Hall thrusters for NASA missions. He is the deputy principal investigator of the High Voltage Hall Accelerator thruster development project, and also supports the Office of Chief Technologist In Space Propulsion project. Wensheng has an M.S. and a Ph.D. in Aerospace Engineering, as well as an M.S. in Nuclear Engineering from the University of the Michigan. He also has a B.S. in Mechanical and Nuclear Engineering from the University of California, Berkeley.

Rohit Shastry is a research engineer at the NASA Glenn Research Center in the Propulsion and Propellants Branch. He is presently the test lead for NASA's Evolutionary Xenon Thruster (NEXT) Long-Duration Test (LDT), and is heavily involved in the design and implementation of numerous plasma diagnostics to further the development of Hall and gridded ion thrusters. Rohit received his B.S.E., M.S. and Ph.D. in Aerospace Engineering from the University of Michigan

Luis R. Piñero received a B.S. in electrical engineering in 1990 from the University of Puerto Rico and a M.S in electrical engineering in 1996 from Cleveland State University. He is a Senior Electrical Engineer in the Propellants and Propulsion Branch at the NASA Glenn Research Center in Cleveland Ohio where since 1990 has been involved in the design and development of high efficiency, lightweight, power processors for electric propulsion systems including arcjets, resistojets, ion thrusters, Hall thrusters, pulsed plasma thrusters and hollow cathodes. Mr. Piñero is a professional engineer in the State of Ohio.
Todd Peterson is a project manager in the Advanced Capabilities Project Office at the NASA Glenn Research Center (GRC). With over 26 years of space flight project experience at NASA GRC, he has extensive propulsion, power and communication system project management experience in human and robotic space flight projects (Space Station, Shuttle/Mir, Deep Space-1, Earth Observer1, Lunar Reconnaissance Orbiter) and development projects (electric propulsion, chemical propulsion, photovoltaic \& dynamic power systems, microgravity research). He has a B.S. in Mechanical Engineering from the University of Akron and an M.S. in Mechanical Engineering from Cleveland State University.

John Dankanich is a project manager of technology development at the Marshall Space Flight Center. John has expertise is in mission and systems analyses, electric propulsion systems, and trajectory optimization. He supports propulsion system development, Mars ascent vehicle design, lunar lander guidance simulations, planetary defense studies, and advanced propulsion design and testing. John has a B.S. in Physics and Aerospace Engineering and an M.S. in Aerospace Engineering from Purdue University.

Alex Mathers is a Program Manager in Electric Propulsion Systems at Aerojet General Corporation with over 15 years of experience in in-space propulsion. He has led the development of Hall thruster system programs including the HiVHAc Hall thruster program activity at Aerojet. In addition, he has experience in development of other propulsion system elements including power processors and propellant management devices. He has a B.S. in Mechanical Engineering and a Masters of Business Administration from the University of Washington. 